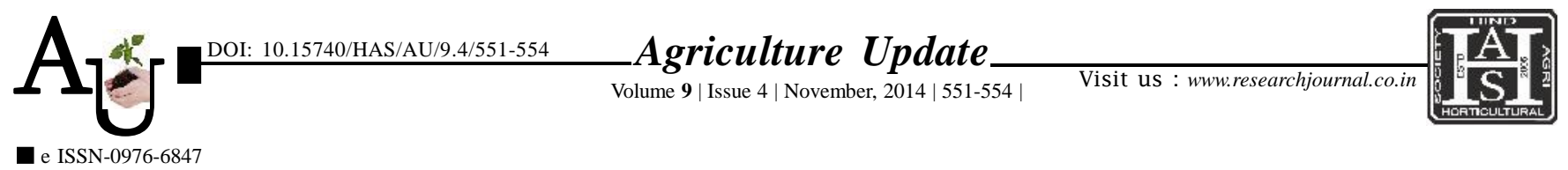

\title{
Research Article Existing organizational climate in Vasantrao Naik Marathwada Krishi Vidyapeeth
}

\begin{abstract}
Article Chronicle:
Received :

19.09.2014;

Revised :

05.10.2014;

Accepted :

15.10.2014

SUMMARY : The present study was conducted in Marathwada region of Maharashtra state. The Vasantrao Naik Marathwada Krishi Vidyapeeth, Parbhani was purposively selected for the study as one of the Agricultural University of Maharashtra State having integrated functioning of teaching, research and extension. 100 respondents were selected from the various faculties of Vasantrao Naik Marathwada Krishi Vidyapeeth, Parbhani on the basis of their involvement. It was observed that more than half respondents had medium age group (53\%) ranging in 38 to 53 years, 55 per cent were educated upto Ph.D. degree level, 55 per cent were Assistant Professor, 58 per cent having medium service experience, 76 per cent of respondents were male, 66 per cent belonged to open category, 58 per cent belonged to rural background, 68 per cent were from medium income group, 76 per cent were in medium category of job satisfaction group, 39 per cent were of medium level achievement motivation. It was observed that 61 per cent of respondents that were in medium level of existing organizational climate. It was observed that the variable such as designation (0.342), annual income (0.259) and job satisfaction (0.289) were positively and significantly related to existing organizational climate.
\end{abstract}

KeY WORdS :

Existing,

Profile,

Organizational

climate
R.P. KADAM, S.M. UMATE, G.S. PAWAR AND R.D. NAWALE

How to cite this article : Kadam, R.P., Umate, S.M., Pawar, G.S. and Nawale, R.D. (2014). Existing organizational climate in Vasantrao Naik Marathwada Krishi Vidyapeeth. Agric. Update, 9(4): 551-554. 